\title{
Metabolic Studies of Radioiodinated Serum Amyloid P Component in Normal Subjects and Patients with Systemic Amyloidosis
}

\author{
Philip N. Hawkins, Richard Wootton, and Mark B. Pepys \\ Immunological Medicine Unit, Department of Medicine and Department of Medical Physics, Royal Postgraduate \\ Medical School, Hammersmith Hospital, London W12 ONN, United Kingdom
}

\begin{abstract}
${ }^{125}$ I-Serum amyloid $P$ component (SAP), injected intravenously into 10 normal subjects, remained predominantly intravascular with mean (SD) $T_{1 / 2}$ (half time) in plasma of 24.5 (5.9) $h$. The fractional catabolic rate of $68(19) \%$ of the plasma pool per day was more rapid than other reported human plasma proteins. All radioactivity was excreted in the urine by $14 \mathrm{~d}$. In 16 patients with monoclonal gammopathy or chronic inflammatory diseases, but without amyloidosis, ${ }^{125} \mathrm{I}-\mathrm{SAP}$ metabolism was normal. However, among 45 patients with biopsy-proven systemic amyloidosis (25, amyloid A type; 20 , amyloid $L$ type), ${ }^{125}$ I-SAP was cleared from the plasma more rapidly, accumulated in the amyloid deposits, and persisted there. The $T_{1 / 2}$ in amyloid, measured directly with ${ }^{131} I-S A P$, was $24 \mathrm{~d}$. Repeat studies after 6-18 mo were notably consistent in normals but changed significantly in amyloid patients, generally correlating with clinical signs of disease progression. Measurements of ${ }^{125} \mathrm{I}$-SAP turnover may thus be of value for diagnosis and monitoring of amyloidosis. Analysis of SAP metabolism in amyloidosis suggests that plasma SAP is in dynamic equilibrium with a very large amyloid pool, and in two autopsies the total mass of SAP in the amyloid deposits was 2,100 and 21,000 mg, respectively. (J. Clin. Invest. 1990. 86:1862-1869.) Key words: amyloidosis - serum amyloid $P$ component • turnover study • diagnosis • monitoring
\end{abstract}

\section{Introduction}

Serum amyloid $\mathrm{P}$ component (SAP) ${ }^{1}$ is a normal plasma glycoprotein, a member of the pentraxin family, the other member of which in man is C-reactive protein (CRP), the classical acute-phase reactant (1). Although the normal function of SAP is not known, the fact that no deficiency of it has yet been described and the fact that very similar homologous molecules are present in the serum of all vertebrates in which

This work was presented in part at the Annual Meeting of the Society of Nuclear Medicine in St. Louis, Missouri, in June, 1989, and at the Annual Meeting of the European Association of Nuclear Medicine in Strasbourg, France, in September, 1989.

Address reprint requests to Dr. P. Hawkins, Immunological Medicine Unit, Royal Postgraduate Medical School, London W12 ONN, United Kingdom.

Received for publication 12 March 1990

1. Abbreviations used in this paper: AA, amyloid A; AL, amyloid L; AP, amyloid P component; CRP, C-reactive protein; SAP, serum AP; TAP, tissue AP; $T_{1 / 2}$, half time; $T_{0}$, time zero.

J. Clin. Invest.

(c) The American Society for Clinical Investigation, Inc.

$0021-9738 / 90 / 12 / 1862 / 08 \quad \$ 2.00$

Volume 86, December 1990, 1862-1869 they have been sought, suggest that it is of physiological importance. A molecule that is immunochemically indistinguishable from SAP, so-called tissue amyloid P component (TAP), is a normal constituent of extracellular tissue matrices. It is an integral component of human glomerular basement membrane, covalently linked to collagen and/or other matrix proteins (2), and is noncovalently associated with the microfibrillar mantle of elastic fibers throughout the body $(3,4)$. It is not known whether TAP is derived from circulating SAP or whether it is produced locally.

SAP is a calcium-dependent lectin with specificity for the cyclic pyruvate acetal of galactose and related sugars (5), and it also binds to sulphated glycosaminoglycans, especially heparan, heparin, and dermatan (6). In addition, SAP is the single plasma protein that specifically undergoes calcium-dependent binding to DNA and chromatin in vitro (7), and interaction with the latter selectively displaces H1-type histones and renders long chromatin soluble at physiological ionic strength (8). SAP also binds to extracellular chromatin in vivo (9) and this may represent a significant part of its normal function. SAP, which has been aggregated in vitro, but not native nonaggregated SAP, specifically binds to fibronectin and C4-binding protein (10), though the functional effects of these interactions are not known.

Apart from its normal properties and physiological distribution, SAP is important as the precursor of amyloid P component (AP), which is a universal nonfibrillar constituent of all known amyloid deposits (11-14). These abnormal extracellular deposits consist predominantly of amyloid fibrils, with characteristic ultrastructural morphology, which are composed of different autologous polypeptide subunits in different forms of the disease $(15,16)$. The amino acid sequence of AP (17) is identical to the sequence of SAP derived from the single copy of its gene present in the human genome $(18,19)$, and we have demonstrated directly, both in mice and in humans, that circulating SAP is the precursor of AP (20-22). This deposition is a consequence of the calcium-dependent binding of SAP to as yet uncharacterized ligands present in amyloid fibrils (23), and it has enabled us to develop a novel method for specifically targeted in vivo radionuclide imaging of amyloid deposits using ${ }^{123}$ I-labeled SAP $(22,24)$. In the course of these studies we made preliminary observations of some of the parameters of SAP metabolism in normal subjects and patients with amyloidosis. We now report here a detailed metabolic analysis of SAP distribution, catabolism, and synthesis based on studies with the longer lived isotopes ${ }^{125} \mathrm{I}$ and ${ }^{131} \mathrm{I}$.

\section{Methods}

Isolation, radiolabeling, and testing of SAP. SAP, over $99 \%$ pure, was isolated (25) from heated $\left(56^{\circ} \mathrm{C}, 30 \mathrm{~min}\right)(26)$ serum of a single accredited donor (UK National Blood Transfusion Service), and was radiolabeled $(27,22)$ with $\mathrm{Na}^{125}$ I (IMS.30; Amersham International, 
Amersham, UK) or $\mathrm{Na}^{131} \mathrm{I}$ (IBS.30; Amersham). Sp act were: ${ }^{125} \mathrm{I}-\mathrm{SAP}$, $5 \mathrm{MBq} / \mathrm{mg} ;{ }^{131} \mathrm{I}$-SAP, $74 \mathrm{MBq} / \mathrm{mg}$, with $99 \%$ of activity precipitable by $10 \% \mathrm{wt} / \mathrm{vol}$ TCA. Iodinated SAP was sterile, nonpyrogenic (22), and caused no adverse effects in vivo. It was indistinguishable from both unlabeled pure SAP and, where appropriate, native SAP in whole untreated normal human serum, in the following tests: nondenaturing and reduced SDS $10 \%$ PAGE $(25,28)^{2}$; analytical Superose gel filtration (Pharmacia Ltd., Milton Keynes, UK); calcium-dependent binding to agarose beads $(5,25)^{2}$, to phosphoethanolamine-Sepharose $(25)^{2}$, and to isolated amyloid A type (AA) and amyloid L (monoclonal light chain) (AL) amyloid fibrils in vitro (23); in vivo distribution and turnover in normal and amyloidotic mice $(20,21)$.

Experimental subjects. $(A) 10$ normal healthy adult volunteers, 5 male and 5 female, aged 22-78 yr. (B) Eight patients with chronic inflammatory disorders and eight with monoclonal gammopathy, diseases associated with systemic amyloidosis but in whom there was no clinical, laboratory, or biopsy evidence of amyloid. $(C) 25$ patients with biopsy-proven reactive systemic AA amyloidosis complicating chronic inflammatory disease. $(D) 20$ patients with biopsy-proven $\mathrm{AL}$ amyloidosis complicating monoclonal gammopathy.

Turnover study protocol. All individuals gave informed consent (Research Ethics Committee, Hammersmith Hospital, London). Administration of radioactivity was approved by the Administration of Radioactive Substances Advisory Committee of the Department of Health and Social Security, England. A history of adverse reactions to iodide or intravenous radiological contrast media was excluded before giving $60 \mathrm{mg}$ bd oral $\mathrm{Kl}$ for $2 \mathrm{~d}$ before and $7 \mathrm{~d}$ after isotope administration.

A precise dose of ${ }^{125} \mathrm{I}-\mathrm{SAP}(\sim 0.15 \mathrm{MBq}, \sim 30 \mu \mathrm{g} \mathrm{SAP}$, effective dose equivalent $\sim 0.05 \mathrm{mSv}$ per study) was given as an intravenous bolus and venous samples were drawn from the other arm 5, 15, 30, 60 min, and 2, 4, 6, and $24 \mathrm{~h}$ afterwards, and then daily for 6 more $\mathrm{d}$. Radioactivity was the same in plasma and in serum and all data are displayed as plasma activity. Over $95 \%$ was TCA precipitable in all samples taken up to $7 \mathrm{~d}$; thereafter only $90-95 \%$ was TCA precipitable in some samples. All urine was also collected for $7 \mathrm{~d}$ and all radioactivity was TCA soluble, even in patients with significant proteinuria. Protein-bound (TCA-precipitated) activity in 1-ml aliquots of all serum samples and total activity in untreated 1-ml aliquots of each 24-h urine collection were counted simultaneously with a standard aliquot of the injected tracer. Results were calculated as percent injected dose per liter of serum (plasma) or urine.

Plasma volumes were estimated from body surface area (29) and by extrapolating plasma radioactivity back to time zero $\left(T_{0}\right)$. Plasma activity was also expressed as a percentage of the notional $T_{0}$ value, and whole-body retention of radioactivity was calculated at daily intervals by subtracting the cumulative activity excreted in the urine from the total injected dose. Extravascular compartment activity was determined daily by subtracting plasma activity from whole-body activity. SAP concentration was estimated (30) in multiple serum samples from each subject.

Curve fitting and metabolic analysis. In 24 patients with systemic amyloid (13 AL, $11 \mathrm{AA}), 8$ patient controls (4 chronic inflammatory diseases, 4 monoclonal gammopathy), and 10 normal volunteers, plasma activity data were analyzed by fitting (31) to one and two compartmental models of behavior of the tracer (32) and to a negative power function of time (33-35). Curve fits were compared by the F-ratio test. Metabolic parameters were derived as follows (36): synthesis rate (i.e., turnover rate in the steady state) from the area under the curve between $T_{0}$ and infinity; the notional $T_{0}$ volume of distribution from the $y$-axis intersect; and the biological half-life and fractional clearance rate from the value of the exponent. Fractional catabolic rate was directly measured as the proportion of radioactivity excreted into the urine divided by mean plasma activity in unit time.

2. Hawkins, P. N., G. A. Tennent, P. Woo, and M. B. Pepys, submitted for publication.
Whole body clearance of ${ }^{131} I-S A P$. One patient with extensive hepatic AL amyloid received $18.5 \mathrm{MBq}(250 \mu \mathrm{g})$ of ${ }^{131} \mathrm{I}-\mathrm{SAP}$, was imaged (IGE Starcam gamma camera; IGE Medical Systems, Slough, UK) immediately and $1,4,9,17$, and $25 \mathrm{~d}$ later, and was studied metabolically with background and isotope decay corrections for $17 \mathrm{~d}$.

Autopsy studies. The distribution of ${ }^{125} \mathrm{I}$-SAP was determined in two patients who died, respectively, 4 mo (patient M. C. AL amyloid, Table IV, no. 4; Table V) and 12 mo (AA amyloid, Table III, no. 1) after injection, and its capacity for calcium-dependent binding to isolated amyloid fibrils in vitro was assessed $(23)^{2}$ after extraction of total AP by homogenization in $140 \mathrm{mM} \mathrm{NaCl}$ containing $10 \mathrm{mM}$ Tris and $10 \mathrm{mM}$ EDTA, pH 8.0, of all tissues which contained amyloid by Congo red staining (37).

\section{Results}

Clearance of ${ }^{125}$ I-SAP in normal subjects. Plasma activity initially fell relatively rapidly, presumably reflecting distribution and equilibration of the labeled protein in the body pool of SAP, leaving, at $6 \mathrm{~h}$, mean (SD), $75(4 \%)$ of the notional $T_{0}$ value in the circulation. Thereafter there was a slower, steady decline throughout the 7-d period of study (Fig. $1 a$ ), continuing for up to $14 \mathrm{~d}$ in two further subjects (data not shown). The half time $\left(T_{1 / 2}\right)$ for clearance of plasma activity was mean (SD), 24.5 (5.9) $\mathrm{h}$, paralleled, with a delay of about $24 \mathrm{~h}$, by the urinary excretion of radioactivity. At $7 \mathrm{~d}$ the whole-body retention was mean (SD), 17 (4)\% of the injected dose and, in two further subjects studied for a longer period, all activity was eliminated by $14 \mathrm{~d}$.

Metabolism and distribution of ${ }^{125}$ I-SAP in normal subjects. In $60 \%$ of the normal subjects the plasma ${ }^{125} \mathrm{I}$-SAP clearance data were best fitted with a negative power function; in
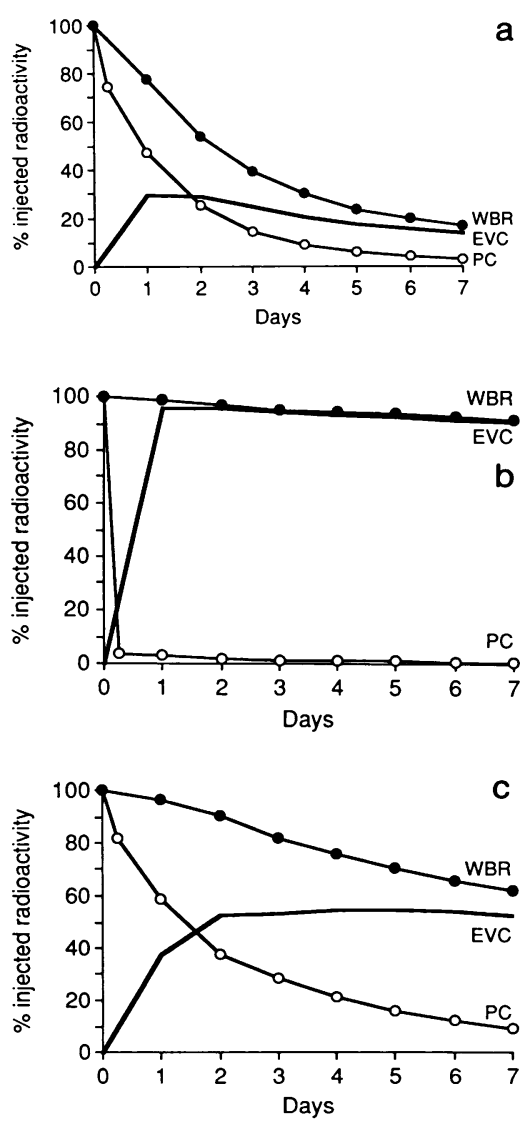

Figure 1. Clearance of ${ }^{125}$ I-SAP in vivo. (a) Each point represents the arithmetic mean of the values in 10 healthy normal subjects; the SDs, which are not shown for reasons of clarity, fell in the range 1.1-8.0\% for PC, $3.8-7.1 \%$ for WBR, and 3.6-7.7 for EVC. (b) Clearance in a single patient with AA amyloidosis and massive amyloid hepatomegaly. (c) Clearance in a single patient with AL amyloidosis and predominantly cardiac involvement. $P C$, plasma clearance; $W B R$, whole body retention; $E V C$, extravascular compartment calculated by subtracting PC from WBR at each point. 


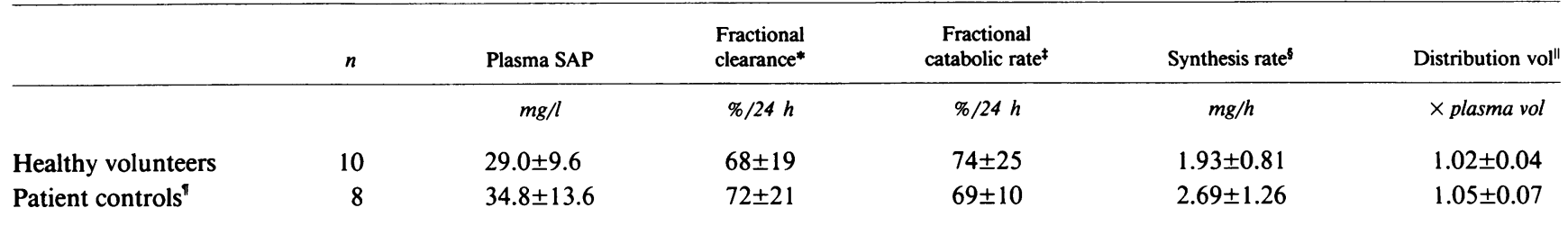

\begin{abstract}
${ }^{*}$ Estimated from fitting the clearance data to a monoexponential function. ${ }^{\ddagger}$ Measured from the cumulative urinary excretion of ${ }^{125} \mathrm{I}$. ${ }^{\S}$ Estimated in each case from the curve fitting function which yielded the statistical "best fit" $(P<0.025)$ to the clearance data, by the method of least squares. "Estimated in each individual from the best fit curve, as above, except where that was produced by negative power function in which case it was derived from the monoexponential function. "Although 16 patient controls were studied, blood samples were not collected throughout the 7-d period in 8 of them and these have therefore been excluded from the complete metabolic analysis.
\end{abstract}

$20 \%$, with a single exponential; and in the remaining $20 \%$, with a two exponential function. When data from the first $24 \mathrm{~h}$ after injection were excluded, the remaining results closely approximated to a single exponential function in all cases.

Total plasma SAP concentrations were constant in all subjects, enabling various metabolic parameters to be calculated (Table I). The fractional clearance rate estimated by curve fitting was essentially the same as the fractional catabolic rate measured directly from the cumulative urinary excretion of radioactivity. The synthesis rate of $S A P$ was $\sim 2 \mathrm{mg} / \mathrm{h}$ and, as expected for a protein of high $M_{\mathrm{r}}, 254,000$, the notional distribution volume obtained by extrapolation of the clearance curves to $T_{0}$ was close to the plasma volume. However, this extrapolated distribution volume is very sensitive to the first few clearance data points and must therefore be regarded as only a nominal value (38), useful for comparison with the pathological situation in amyloidosis rather than a reliable absolute quantitation.

Studies of ${ }^{125}$ I-SAP in patient controls. In 16 patients with various disorders predisposing to amyloidosis, but in whom there was no clinical or pathological evidence of amyloid, plasma SAP levels were within normal limits and were constant throughout the studies of ${ }^{125}$ I-SAP turnover. The results of these studies were not significantly different from the healthy volunteers (Table I), all values falling within 2 SD about the mean of the normal control group, even in three patients who had acute phase responses at the time of the study, with serum CRP values of 16,30 , and $46 \mathrm{mg} / \mathrm{liter}$, respectively. At the end of the initial rapid phase of distribution/clearance there was mean (SD), 72 (5)\% of the notional $T_{0}$ value in the circulation and the $T_{1 / 2}$ of the subsequent steady monoexponential phase was $22.8(5.7) \mathrm{h}$. At $7 \mathrm{~d}$ the whole body retention was $15(8) \%$ of the injected dose.

Model of normal SAP metabolism. Using the two-exponential function to fit the clearance data it is possible to construct a simple two-compartment model for normal SAP metabolism in which the bulk of the SAP is in the plasma compartment, in free exchange with a relatively small extravascular compartment, and SAP is catabolized and replaced by de novo synthesis at a steady rate. Typical values calculated for three normal subjects in whom the clearance results corresponded most closely to the two-exponential function are shown in Table II.

Clearance of ${ }^{125}$ I-SAP in patients with amyloidosis. The plasma SAP values (mean [SD]) in patients with amyloidosis were not significantly different from normal: AL amyloid, 25.2 (11.6) $\mathrm{mg} /$ liter, $n=20$; AA amyloid, 33.4 (12.1) mg/liter, $n$
$=25$. However, in most of these patients the clearance of ${ }^{125} \mathrm{I}-$ SAP was abnormal. In patients with very extensive deposits, especially those with amyloid hepatomegaly and/or splenomegaly, the initial plasma clearance of SAP was greatly accelerated; in extreme cases, over $90 \%$ of the injected dose left in the circulation within minutes (Fig. $1 b$ and Fig. 2; Tables III and IV). However, even when clearance was less rapid, urinary excretion of tracer was reduced and whole-body retention at 7 $\mathrm{d}$ was increased (Fig. $1 c$ and Fig. 2; Tables III and IV). This was a result of increased accumulation of ${ }^{125}$ I-SAP in the extravascular compartment (Figs. 1 and 2; Tables III and IV).

Persistence of SAP in amyloid deposits. Animal experiments $(20,21,39)$ and our imaging and autopsy studies of patients injected with ${ }^{123}$ I-SAP $(22,24)$, have demonstrated that the extravascular accumulation and retention of activity represent the specific deposition of circulating SAP as AP in amyloid deposits. Whole-body scanning and metabolic measurements after injection of ${ }^{131}$ I-SAP into an individual with massive amyloid hepatomegaly both showed that the $T_{1 / 2}$ of SAP in the liver amyloid was $24 \mathrm{~d}$ (Fig. 3), and confirmed that the only significant route of excretion of label was the urine. In a patient who died $4 \mathrm{mo}$ after injection of ${ }^{125} \mathrm{I}$-SAP, $5 \%$ of the injected dose was recovered in the form of whole, unaltered, functionally intact molecules by elution of the amyloid-laden spleen, liver, and heart obtained at autopsy.

Metabolic analysis of ${ }^{125}$ I-SAP in amyloidosis. The plasma activity data in amyloid patients corresponded most closely to a negative power function in all cases, except one who, clinically, had only minor deposits. The poorest curve fits were seen in patients with the most extensive amyloid by clinical criteria. The significance of these findings is not clear but it means that simple models based on low order exponential

Table II. Two-Compartment Steady State (Two-Exponential) Model for Normal SAP Metabolism

\begin{tabular}{ccccc}
\hline Subject & $\begin{array}{c}\text { Intravascular } \\
\text { compartment C1 } \\
\text { SAP }\end{array}$ & $\begin{array}{c}\text { Extravascular } \\
\text { compartment C2 } \\
\text { SAP }\end{array}$ & $\begin{array}{c}\text { Rate of } \\
\text { exchange } \\
\text { C1-C2 SAP }\end{array}$ & $\begin{array}{c}\text { Synthesis } \\
\text { rate SAP }\end{array}$ \\
\hline & & $m g$ & \multicolumn{2}{c}{$m g / h$} \\
1 & 95.7 & 24.1 & 5.1 & 3.0 \\
2 & 49.1 & 8.2 & 3.0 & 1.2 \\
3 & 46.5 & 10.2 & 1.9 & 1.0 \\
\hline
\end{tabular}



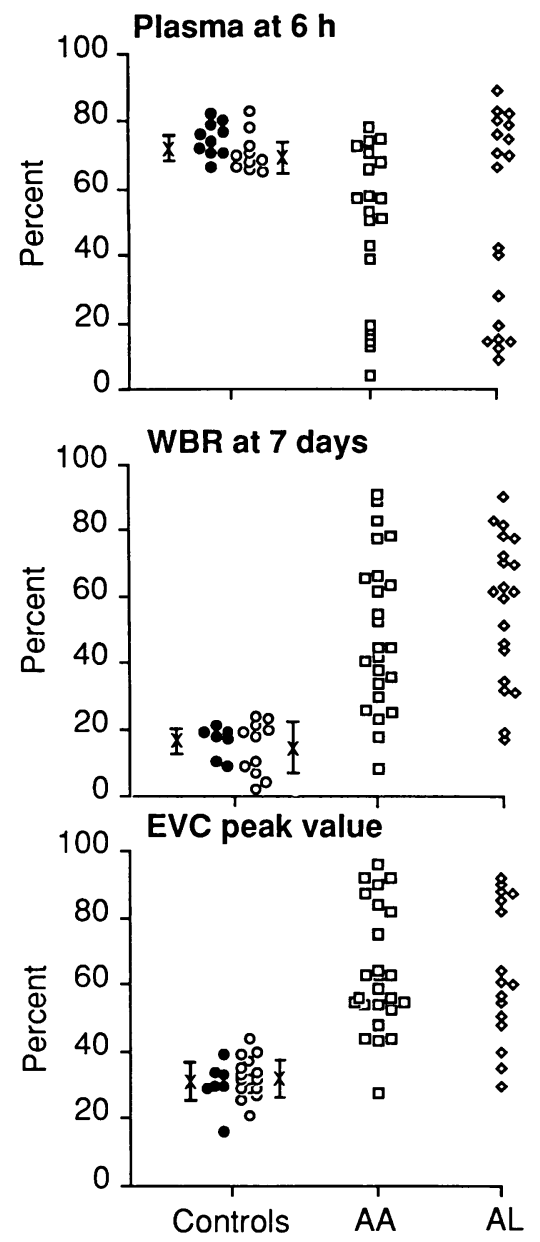

Figure 2. Turnover in vivo of ${ }^{125}$ I-SAP in controls and patients with amyloidosis. Each point represents the value in a single individual: $\bullet$. normal healthy controls; $\circ$, patient controls; $\square$, patients with AA amyloidosis; $\diamond$, patients with $\mathrm{AL}$ amyloidosis. The mean and SD of the control groups are indicated by $x$ with error bars. (Top) Plasma activity at $6 \mathrm{~h}$; (middle) whole-body retention at $7 \mathrm{~d}$; (bottom) peak value in the extravascular compartment. See also Tables III and IV.
Table III. Turnover of ${ }^{125}$ I-SAP in Patients with AA Amyloidosis

\begin{tabular}{|c|c|c|c|c|}
\hline \multirow[b]{3}{*}{ Normal range } & \multicolumn{4}{|c|}{ Percentage of injected radioactivity } \\
\hline & \multirow[b]{2}{*}{$\begin{array}{l}\text { Plasma, } 6 \mathrm{~h} \\
>65\end{array}$} & \multirow[b]{2}{*}{$\begin{array}{l}\text { Whole body, } \\
7 \mathrm{~d}<25\end{array}$} & \multicolumn{2}{|c|}{ Extravascular compartment } \\
\hline & & & $\begin{array}{c}\text { Peak value } \\
<45\end{array}$ & Day achieved \\
\hline \multicolumn{5}{|l|}{ Patient No. } \\
\hline 1 & 4 & 92 & 96 & 1 \\
\hline 2 & 43 & 53 & 63 & 2 \\
\hline 3 & 71 & 30 & 44 & 2 \\
\hline 4 & 4 & 84 & 92 & 1 \\
\hline 5 & 66 & 34 & 44 & 2 \\
\hline 6 & 50 & 26 & 55 & 1 \\
\hline 7 & 14 & 90 & 90 & 1 \\
\hline 8 & 74 & 38 & 55 & 2 \\
\hline 9 & 18 & 67 & 84 & 1 \\
\hline 10 & 4 & 79 & 92 & 1 \\
\hline 11 & 78 & 64 & 59 & 4 \\
\hline 12 & 57 & 45 & 48 & 2 \\
\hline 13 & 53 & 42 & 64 & 1 \\
\hline 14 & 58 & 41 & 56 & 1 \\
\hline 15 & 19 & 62 & 82 & 1 \\
\hline 16 & 66 & 25 & 43 & 1 \\
\hline 17 & 68 & 45 & 54 & 2 \\
\hline 18 & 51 & 42 & 56 & 1 \\
\hline 19 & 75 & 8 & 28 & 1 \\
\hline 20 & 73 & 23 & 53 & 1 \\
\hline 21 & 53 & 18 & 54 & 1 \\
\hline 22 & 16 & 66 & 75 & 1 \\
\hline 23 & 39 & 36 & 63 & 1 \\
\hline 24 & 57 & 55 & 63 & 2 \\
\hline 25 & 13 & 78 & 87 & 1 \\
\hline
\end{tabular}

tively, were found. These results greatly exceed the values calculated for the extravascular compartment from the exponential model. By analogy with the behavior of radiocalcium (40) they suggest that in addition to the "superficial" AP compartment, in rapid and free exchange with plasma SAP, there may be a "deep" AP compartment, exchange with which is much slower. The prolonged persistence of ${ }^{125}$ I-SAP within amyloid deposits supports this concept, but it could also be explained by the existence of a continuum between superficial AP and deep AP sequestrated within very extensive deposits.

Diagnostic implications of ${ }^{125} I-S A P$ turnover in systemic amyloidosis. The turnover of ${ }^{125} \mathrm{I}$-SAP in the group of amyloidosis patients as a whole was significantly different from that in the control groups. Taking a value outside $2 \mathrm{SD}$ about the mean of the normal controls as abnormal, the plasma activity at $6 \mathrm{~h}$ was abnormal in $62 \%$ of the amyloid patients, the whole-body activity at $7 \mathrm{~d}$ was abnormal in $89 \%$, and the extravascular activity at $7 \mathrm{~d}$ was abnormal in $91 \%$. Only three patients $(6.6 \%)$ had normal values for all three variables. Furthermore in a number of amyloid patients the peak value for extravascular activity was reached only between days 2 and 5 (Fig. 1; Tables III and IV) compared with days 1 and 2 in controls. None of the patient controls differed from normals and in this study these alterations in SAP turnover were therefore $100 \%$ specific for amyloidosis. In an additional set of 26 available at post-mortem, and 2,100 and $21,000 \mathrm{mg}$, respec- 
Table IV. Turnover of ${ }^{125}$ I-SAP in Patients with AL Amyloidosis

\begin{tabular}{|c|c|c|c|c|}
\hline \multirow[b]{3}{*}{$\begin{array}{l}\text { Normal } \\
\text { range }\end{array}$} & \multicolumn{4}{|c|}{ Percentage of injected radioactivity } \\
\hline & \multirow[b]{2}{*}{$\underset{>65}{\text { Plasma, } 6 \mathrm{~h}}$} & \multirow[b]{2}{*}{$\begin{array}{l}\text { Whole body, } \\
7 \mathrm{~d}<25\end{array}$} & \multicolumn{2}{|c|}{ Extravascular compartment } \\
\hline & & & $\begin{array}{l}\text { Peak value } \\
<45\end{array}$ & Day achieved \\
\hline \multicolumn{5}{|l|}{ Patient no. } \\
\hline 1 & 82 & 62 & 55 & 4 \\
\hline 2 & 12 & 78 & 88 & 1 \\
\hline 3 & 71 & 46 & 57 & 4 \\
\hline 4 & 42 & 70 & 64 & 5 \\
\hline 5 & 70 & 52 & 64 & 3 \\
\hline 6 & 14 & 73 & 82 & 1 \\
\hline 7 & 19 & 82 & 87 & 1 \\
\hline 8 & 15 & 84 & 90 & 1 \\
\hline 9 & 75 & 17 & 35 & 1 \\
\hline 10 & 28 & 71 & 85 & 1 \\
\hline 11 & 14 & 60 & 85 & 1 \\
\hline 12 & 28 & 62 & 61 & 1 \\
\hline 13 & 67 & 35 & 40 & 3 \\
\hline 14 & 80 & 31 & 30 & 3 \\
\hline 15 & 40 & 63 & 60 & 1 \\
\hline 16 & 83 & 91 & 92 & 1 \\
\hline 17 & 79 & 32 & 48 & 2 \\
\hline 18 & 76 & 44 & 51 & 3 \\
\hline 19 & 89 & 19 & 30 & 2 \\
\hline 20 & 9 & 79 & 90 & 1 \\
\hline
\end{tabular}

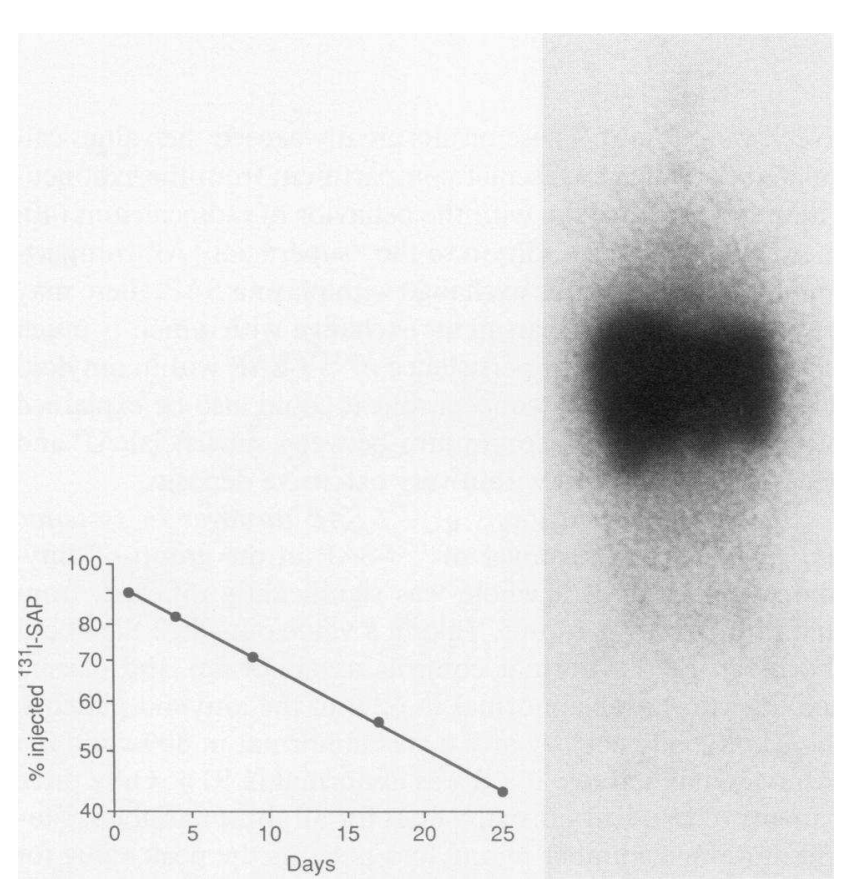

Figure 3. Persistence of ${ }^{131} \mathrm{I}$-SAP in amyloid. (Left) Each point is the geometric mean liver activity measured by scanning, corrected for isotope decay, in a single patient with massive AL amyloid hepatomegaly. The $T_{1 / 2}$ was $24 \mathrm{~d}$. (Right) Scintigraphic whole body image at $24 \mathrm{~h}$ after intravenous injection of ${ }^{131} \mathrm{I}$-SAP in same patient. patient controls no abnormalities of turnover of ${ }^{123} \mathrm{I}$-SAP were seen (24) and the presence of amyloid is thus, so far, the only condition which produces the observed alterations. However, the present value for "diagnostic sensitivity" reflects the particular amyloid patients who were studied. Inclusion of more individuals with only minor deposits would lead to more results within the normal range, while in a group with major deposits all would be expected to give abnormal results.

Turnover studies of ${ }^{125} \mathrm{I}$-SAP were repeated in 3 normal subjects and in 12 amyloid patients at intervals of 6-18 mo after their first investigation. The results in normals were notably constant. However, in some of the patients there was more rapid early plasma clearance, increased whole-body retention, and increased extravascular accumulation, which usually, but not always, correlated with clinical assessment of deterioration (Table V). Such imperfect correlation is not surprising since the SAP turnover presumably reflects the quantity of amyloid present, which may not be paralleled by the extent of organ dysfunction. One patient in particular, M.C. with AL amyloid, showed dramatically increased clearance of SAP and tissue accumulation after an interval of 6 mo (Fig. 4), when there was little evidence of clinical change, but she died 4 mo after the second study.

In preliminary studies, plasma activity and whole-body counts were measured 1 mo or more after injection of ${ }^{125} \mathrm{I}-\mathrm{SAP}$ or ${ }^{131}$ I-SAP. In normals and patients without amyloid all the labeled SAP had been catabolized and the radioiodine excreted by $14 \mathrm{~d}$. However, in patients with even small amounts of amyloid, some labeled SAP was retained, and was detected either by whole-body counting, or in the plasma, with which it remained in dynamic equilibrium.

Table V. Serial ${ }^{125}$ I-SAP Turnover Studies in Systemic Amyloidosis

\begin{tabular}{|c|c|c|c|c|c|}
\hline Patient & Amyloid & Interval & EPC & $\begin{array}{c}\text { WBR } 7 \mathrm{~d} \\
\% \text { injected dose }\end{array}$ & $\begin{array}{c}\text { EVC peak } \\
\text { (at day) }\end{array}$ \\
\hline
\end{tabular}

Patients with clinical deterioration

$\begin{array}{llrlll}\text { E.M. } & \text { AA } & 12 & 43 \rightarrow 37 & 53 \rightarrow 58 & 63(2) \rightarrow 69(1) \\ \text { K.L. } & \text { AA } & 12 & 71 \rightarrow 68 & 30 \rightarrow 33 & 44(2) \rightarrow 51(1) \\ \text { J.R. } & \text { AL } & 12 & 82 \rightarrow 75 & 62 \rightarrow 71 & 55(5) \rightarrow 66(3) \\ \text { T.K. } & \text { AL } & 9 & 75 \rightarrow 67 & 17 \rightarrow 34 & 35(1) \rightarrow 49(2)\end{array}$

Patients with no clinical change

$\begin{array}{llrlcl}\text { J.C. } & \text { AA } & 12 & 66 \rightarrow 59 & 34 \rightarrow 38 & 44(1) \rightarrow 45(1) \\ \text { R.H. } & \text { AA } & 9 & 53 \rightarrow 52 & 40 \rightarrow 39 & 64(1) \rightarrow 61(1) \\ \text { T.M. } & \text { AA } & 9 & 14 \rightarrow 15 & \text { NA } & \text { NA } \\ \text { F.M. } & \text { AL } & 6 & 76 \rightarrow 74 & 44 \rightarrow 52 & 51(2) \rightarrow 55(1) \\ \text { B.G. } & \text { AL } & 12 & 80 \rightarrow 73 & 31 \rightarrow 37 & 30(2) \rightarrow 37(1) \\ \text { M.C. } & \text { AL } & 6 & 42 \rightarrow 26 & 70 \rightarrow 74 & 64(5) \rightarrow 80(1)\end{array}$

Patients with clinical improvement
A.B. AA $6 \quad 76 \rightarrow 80$
H.C. AL $\quad 18 \quad 83 \rightarrow 79$
$8 \rightarrow 4$
$28(1) \rightarrow 26(1)$

Normal volunteers

$\begin{array}{cccccc}1 & - & 15 & 72 \rightarrow 71 & 18 \rightarrow 19 & 38(1) \rightarrow 36(1) \\ 2 & - & 15 & 80 \rightarrow 81 & 18 \rightarrow 17 & 30(2) \rightarrow 32(1) \\ 3 & - & 12 & 82 \rightarrow 81 & 8 \rightarrow 10 & 17(2) \rightarrow 23(1) \\ \text { Mean normal value } & & 75 & 17 & 30(1)\end{array}$

EPC, early plasma clearance; WBR, whole body retention of radioactivity; EVC, radioactivity in extravascular compartment. 


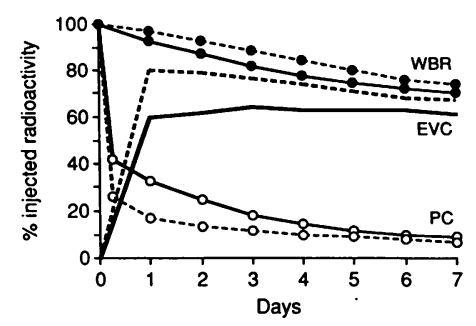

Figure 4. Sequential clearance study of ${ }^{125} \mathrm{I}$ SAP in single patient (MC, Table V) with AL amyloidosis. $P C$, plasma clearance; $W B R$, whole body retention; $E V C$, extravascular compartment calculated by subtracting PC from WBR at each point. Solid lines, initial study; broken lines, follow-up study 6 mo later.

\section{Discussion}

We describe here for the first time the plasma clearance of radioiodinated human SAP. The labeled protein was structurally intact and fully active functionally, including its capacity for specific calcium-dependent ligand binding in vitro. Furthermore its handling in vivo by both normal and amyloidotic mice was identical to that of both unlabeled purified human SAP and completely untreated SAP administered by injection of whole normal human serum. There is no evidence of either genetic or phenotypic polymorphism of SAP.The behavior of the labeled isologous tracer used here can therefore be confidently taken to represent the behavior of autologous SAP in situ in the body.

The fractional catabolic rate of SAP was $\sim 70 \%$ of the plasma pool per day, and it was therefore more rapidly catabolized in normal subjects than other plasma proteins studied hitherto (41-47). All the radioiodine-labeled breakdown products of the tracer were excreted in the urine and the injected dose was completely eliminated after $\sim 14 \mathrm{~d}$. The estimated normal synthesis rate was $\sim 2 \mathrm{mg} / \mathrm{h}$. Not surprisingly for such a large molecule, $M_{\mathrm{r}} 254,000$, it was predominantly restricted to the vascular compartment, although calculations from a two-exponential, two-compartment model of its distribution indicated that up to $\sim 25 \%$ may be in an extravascular compartment in free and rapid exchange with the circulation. However, no evidence was obtained of interchange between SAP and the normal TAP of extracellular matrix structures. If TAP is derived from circulating SAP this must take place either too slowly or at too low a level to have been detected in these studies.

In patients with systemic $\mathrm{AA}$ or $\mathrm{AL}$ amyloidosis, striking alterations of SAP turnover were observed. After injection, the labeled SAP rapidly and specifically localized to the amyloid deposits and was then retained there for prolonged periods. The amount of tracer that accumulated in amyloid and the speed of its deposition generally correlated closely with clinical assessment of the size and extent of amyloid deposits. In cases with massive amyloid hepatomegaly and/or splenomegaly virtually all of the injected dose was taken up in the amyloid within minutes.

In patients with diseases predisposing to amyloidosis but in whom there was no clinical, laboratory, or pathological evidence of amyloid, the turnover of SAP was indistinguishable from controls. Monitoring of labeled SAP clearance and excretion may therefore be useful in the diagnosis of amyloidosis.
Furthermore, repeat studies at intervals of 6-18 mo provided clear evidence of increased amyloid deposition in some patients, compared with remarkable stability of all parameters of SAP metabolism in normal subjects. Although clearly there is scope for more work, this approach may be useful for monitoring in vivo the extent and progression of amyloid per se, rather than just its effects on affected tissues and organs.

Once labeled SAP was deposited as AP within amyloid deposits it was apparently protected from the normal rapid catabolism of SAP in the plasma compartment. Direct measurement of the persistence of ${ }^{131}$ I-SAP in the liver of a patient with massive amyloid hepatomegaly revealed a $T_{1 / 2}$ of $24 \mathrm{~d}$, compared with the $T_{1 / 2}$ of plasma SAP of $24.5 \mathrm{~h}$. This remarkable result was corroborated by measurements of urinary excretion of ${ }^{131} \mathrm{I}$, and, in another patient who died 4 mo after a ${ }^{125}$ I-SAP study, by the presence within the amyloidotic organs of $\sim 5 \%$ of the injected dose in the form of whole, intact, fully functional SAP molecules. In amyloidosis, therefore, the circulating SAP is in exchange with both a freely accessible superficial extravascular pool of SAP, as in normals, and also a deep pool of AP in the amyloid deposits. It is not clear, however, whether this is a single deep pool in which some labeled SAP persists for prolonged periods simply because of its size, or whether there are discrete "layers" or "zones" within amyloid deposits to which SAP is more tightly bound.

The size of the AP pool is also remarkable, up to $21 \mathrm{~g}$, and this level of accumulation must reflect increased SAP production, although it was difficult to estimate accurately because the grossly altered plasma clearance kinetics cannot be well fitted to the usual exponential models of plasma protein metabolism. Nevertheless, at the rate of, say, $1 \mathrm{mg} / \mathrm{h}$, which is well within the range estimated for increased SAP production in amyloid patients, it would take $\sim 3$ yr to accumulate an AP pool of this size, a period compatible with the known natural history of the disorder.

It has long been known that the plasma SAP concentration is normal in patients with amyloidosis (48-50) and this was confirmed here. Given the demonstrated rapid clearance and deposition of SAP in amyloid, the massive accumulation of $\mathrm{AP}$, and the accelerated synthesis of SAP, there evidently is a tightly regulated homeostatic feedback mechanism that keeps the plasma SAP concentration within normal limits. This contrasts sharply with the behavior of CRP, plasma levels of which can increase by $>3,000$-fold in the acute phase response (1), and suggests that maintenance of a constant circulating concentration may be important for the normal function of SAP.

\section{Acknowledgments}

We thank Ms. Suzanne Richardson for help with the turnover studies, Ms. Belinda Henderson for the scintigraphic imaging, and Ms. Beth Sontrop for expert preparation of the manuscript.

This work was supported by Medical Research Council Programme Grant PG7900510 to Dr. Pepys. Dr. Hawkins was an MRC Training Fellow.

\section{References}

1. Pepys, M. B., and M. L. Baltz. 1983. Acute phase proteins with special reference to $\mathrm{C}$-reactive protein and related proteins (pentaxins) and serum amyloid A protein. Adv. Immunol. 34:141-212. 
2. Dyck, R. F., C. M. Lockwood, M. Kershaw, N. McHugh, V. C. Duance, M. L. Baltz, and M. B. Pepys. 1980. Amyloid P-component is a constituent of normal human glomerular basement membrane. $J$. Exp. Med. 152:1162-1174.

3. Breathnach, S. M., S. M. Melrose, B. Bhogal, F. C. de Beer, R. F. Dyck, G. Tennent, M. M. Black, and M. B. Pepys. 1981. Amyloid P component is located on elastic fibre microfibrils of normal human tissues. Nature (Lond.). 293:652-654.

4. Breathnach, S. M., M. B. Pepys, and H. Hinter. 1989. Tissue amyloid $\mathbf{P}$ component in normal human dermis is non-covalently associated with elastic fiber microfibrils. J. Invest. Dermatol. 92:53-58.

5. Hind, C. R. K., P. M. Collins, D. Renn, R. B. Cook, D. Caspi, M. L. Baltz, and M. B. Pepys. 1984. Binding specificity of serum amyloid $\mathrm{P}$ component for the pyruvate acetal of galactose. J. Exp. Med. 159:1058-1069.

6. Hamazaki, H. 1987. $\mathrm{Ca}^{2+}$-mediated association of human serum amyloid $P$ component with heparan sulfate and dermatan sulfate. $J$. Biol. Chem. 262:1456-1460.

7. Pepys, M. B., and P. J. G. Butler. 1987. Serum amyloid P component is the major calcium-dependent specific DNA binding protein of the serum. Biochem. Biophys. Res. Commun. 148:308-313.

8. Butler, P. J. G., G. A. Tennent, and M. B. Pepys. 1990. Pentraxin-chromatin interactions: serum amyloid $P$ component specifcally displaces $\mathrm{H} 1$-type histones and solubilizes native long chromatin. J. Exp. Med. 172:13-18.

9. Breathnach, S. M., H. Kofler, N. Sepp, J. Ashworth, D. Woodrow, M. B. Pepys, and H. Hinter. 1989. Serum amyloid P component binds to cell nuclei in vitro and to in vivo deposits of extracellular chromatin in systemic lupus erythematosus. J. Exp. Med. 170:14331438.

10. de Beer, F. C., M. L. Baltz, S. Holford, A. Feinstein, and M. B. Pepys. 1981. Fibronectin and C4-binding protein are selectively bound by aggregated amyloid P component. J. Exp. Med. 154:1134-1149.

11. Westermark, P., T. Shirahama, M. Skinner, P. Noren, and A. S. Cohen. 1981. Amyloid P-component (protein AP) in localized amyloidosis as revealed by an immunocytochemical method. Histochemistry. 71:171-175.

12. Pepys, M. B., M. Baltz, F. C. de Beer, R. F. Dyck, S. Holford, S. M. Breathnach, M. M. Black, C. R. F. Tribe, D. J. Evans, and A. Feinstein. 1982. Biology of serum amyloid P component. Ann. NY Acad. Sci. 389:286-297.

13. Coria, F., E. Castano, F. Prelli, M. Larrondo-Lillo, S. van Duinen, M. L. Shelanski, and B. Frangione. 1988. Isolation and characterization of amyloid $\mathbf{P}$ component from Alzheimer's disease and other types of cerebral amyloidosis. Lab. Invest. 58:454-458.

14. Dische, F. E., C. Wernstedt, G. T. Westermark, P. Westermark, M. B. Pepys, J. A. Rennie, S. G. Gilbey, and P. J. Watkins. 1988. Insulin as an amyloid-fibril protein at sites of repeated insulin injections in a diabetic patient. Diabetologia. 31:158-161.

15. Glenner, G. G. 1980. Amyloid deposits and amyloidosis-the $\beta$-fibrilloses. I \& II. N. Engl. J. Med. 302:1283-1292 \& 1333-1343.

16. Pepys, M. B. 1988. Amyloidosis. In Immunological Diseases Vol. 1. 4th ed. M. Samter, D. W. Talmage, M. M. Frank, K. F. Austen, and H. N. Claman, editors. Little, Brown \& Co., Boston. 631-674.

17. Prelli, F., M. Pras, and B. Frangione. 1985. The primary structure of human tissue amyloid $P$ component from a patient with primary idiopathic amyloidosis. J. Biol. Chem. 260:12895-12898.

18. Mantzouranis, E. C., S. B. Dowton, A. S. Whitehead, M. D. Edge, G. A. P. Bruns, and H. R. Colten. 1985. Human serum amyloid $P$ component. cDNA isolation, complete sequence of pre-serum amyloid $\mathrm{P}$ component, and localization of the gene to chromosome $1 . J$. Biol. Chem. 280:7752-7756.

19. Ohnishi, S., S. Maeda, K. Shimada, and T. Arao. 1986. Isolation and characterization of the complete complementary and genomic DNA sequences of human serum amyloid P component. J. Biochem. (Tokyo). 100:849-858.
20. Baltz, M. L., D. Caspi, D. J. Evans, I. F. Rowe, C. R. K. Hind, and M. B. Pepys. 1986. Circulating serum amyloid $P$ component is the precursor of amyloid $\mathrm{P}$ component in tissue amyloid deposits. Clin. Exp. Immunol. 66:691-700.

21. Hawkins, P. N., M. J. Myers, A. A. Epenetos, D. Caspi, and M. B. Pepys. 1988. Specific localization and imaging of amyloid deposits in vivo using ${ }^{123} \mathrm{I}$-labeled serum amyloid $\mathrm{P}$ component. J. Exp. Med. 167:903-913.

22. Hawkins, P. N., M. J. Myers, J. P. Lavender, and M. B. Pepys. 1988. Diagnostic radionuclide imaging of amyloid: biological targeting by circulating human serum amyloid P component. Lancet. i:14131418 .

23. Pepys, M. B., R. F. Dyck, F. C. de Beer, M. Skinner, and A. S. Cohen. 1979. Binding of serum amyloid P component (SAP) by amyloid fibrils. Clin. Exp. Immunol. 38:284-293.

24. Hawkins, P. N., J. P. Lavender, and M. B. Pepys. 1990. Evaluation of systemic amyloidosis by scintigraphy with ${ }^{123}$ I-labeled serum amyloid P component. N. Engl. J. Med. 323:508-513.

25. de Beer, F. C., and M. B. Pepys. 1982. Isolation of human $\mathrm{C}$-reactive protein and serum amyloid $\mathrm{P}$ component. J. Immunol. Methods. 50:17-31.

26. McDougal, J. S., L. S. Martin, S. P. Cort, M. Mozen, C. M. Heldebrant, and B. L. Evatt. 1985. Thermal inactivation of the acquired immunodeficiency syndrome virus, human $\mathrm{T}$ lymphotropic virus-III/lymphadenopathy-associated virus, with special reference to antihemophilic factor. J. Clin. Invest. 76:875-877.

27. Mather, S. J., and B. G. Ward. 1987. High efficiency iodination of monoclonal antibodies for radiotherapy. J. Nucl. Med. 28:10341036.

28. Laemmli, U. K. 1970. Cleavage of structural proteins during the assembly of the head of bacteriophage T4. Nature (Lond.). 227:680-685.

29. Najean, Y., and R. Cacchione. 1977. Blood volumes in health and disease. Clin. in Haematol. 6:543-566.

30. Pepys, M. B., A. C. Dash, R. E. Markham, H. C. Thomas, B. D. Williams, and A. Petrie. 1978. Comparative clinical study of protein SAP (amyloid P component) and C-reactive protein in serum. Clin. Exp. Immunol. 32:119-124.

31. Ross, G. J. S. 1980. MLP Maximum Likelihood Program. Lawes Agricultural Trust (Rothampsted Fxperimental Station), Harpenden, Herts., UK. 150 pp.

32. Matthews, C. M. E. 1957. The theory of tracer experiments with ${ }^{131}$ I-labelled plasma proteins. Phys. Med. Biol. 2:36-53.

33. Wise, M. E. 1977. The form and interpretation of clearance curves for injected radioisotopes based on negative power laws, especially for ${ }^{47} \mathrm{Ca}$ and estimating bone accretion rate. Curr. Top. Radiat. Res. Q. 12:63-82.

34. Norwich, K. H., and S. Siu. 1982. Power functions in physiology and pharmacology. J. Theor. Biol. 95:387-398.

35. Wise, M. E. 1985. Negative power functions of time in pharmacokinetics and their implications. J. Pharmacokinet. Biopharm 13:309-346.

36. Wootton, R., P. A. Flecknell, and A. Mehta. 1987. A comparison in neonatal piglets of model-dependent and model-independent methods for measuring glucose turnover. Clin. Phys. Physiol. Meas. 8:355-365.

37. Puchtler, H., F. Sweat, and M. Levine. 1962. On the binding of Congo red by amyloid. J. Histochem. Cytochem. 10:355-364.

38. Norwich, K. H. 1977. Molecular Dynamics in Biosystems. Pergamon Press, Oxford. 405 pp.

39. Caspi, D., S. Zalzman, M. Baratz, Z. Teitelbaum, M. Yaron, M. Pras, M. L. Baltz, and M. B. Pepys. 1987. Imaging of experimental amyloidosis with ${ }^{131} \mathrm{I}$-serum amyloid $\mathrm{P}$ component. Arthritis Rheum. 30:1303-1306.

40. Marshall, J. H. 1969. Chapter 1. In Mineral Metabolism. Vol. 3. C. L. Comar and F. Bronner, editors. Academic Press, New York $1-122$. 
41. Jarnum, S. 1975. Turnover of plasma proteins. J. Clin. Pathol. (Lond.). 6:13-21.

42. Socolow, E. L., K. A. Woeber, R. H. Purdy, M. T. Holloway, and S. H. Ingbar. 1965. Preparation of $I^{131}$-labeled human serum prealbumin and its metabolism in normal and sick patients. J. Clin. Invest. 44:1600-1609.

43. Charlesworth, J. A., D. G. Williams, E. Sherington, P. J. Lachmann, and D. K. Peters. 1974. Metabolic studies of the third component of complement and the glycine-rich beta glycoprotein in patients with hypocomplementemia. J. Clin. Invest. 53:1578-1587.

44. Nexo, E., and P. Gimsing. 1975. Turnover in humans of iodineand cobalamin-labeled transcobalamin I and of iodine-labeled albumin. Scand. J. Clin. Lab. Invest. 35:391-398.

45. Cavalieri, R. R., F. A. McMahon, and J. N. Castle. 1975. Preparation of ${ }^{125}$ I-labeled human thyroxine-binding alpha globulin and its turnover in normal and hypothyroid subjects. J. Clin. Invest. 56:79-87.
46. Potter, B. J., E. Elias, and E. A. Jones. 1976. Hypercatabolism of the third component of complement in patients with primary biliary cirrhosis. J. Lab. Clin. Med. 88:427-439.

47. Carlson, T. H., T. L. Simon, and A. C. Atencio. 1985. In vivo behavior of human radioiodinated antithrombin III: distribution among three physiologic pools. Blood. 66:13-19.

48. Cathcart, E. S., F. A. Wollheim, and A. S. Cohen. 1967. Immunoassay of $\mathrm{P}$ component in amyloidotic sera. Proc. Soc. Exp. Biol. Med. 125:1123-1125.

49. Skinner, M., J. L. Vaitukaitis, A. S. Cohen, and M. D. Benson. 1979. Serum amyloid $P$ component levels in amyloidosis, connective tissue diseases, infection, and malignancy as compared to normal serum. J. Lab. Clin. Med. 94:633-638.

50. Gertz, M. A., M. Skinner, A. S. Cohen, and R. A. Kyle. 1983. Nephelometric measurement of human serum amyloid $\mathrm{P}$ component (SAP). J. Lab. Clin. Med. 102:773-778. 